\title{
"É UMA QUESTÃO DE GERAÇÃO, EU NÃO USO MEU CORPO ASSIM": DIFERENÇAS GERACIONAIS E DIFERENTES FEMINISMOS A PARTIR DA MARCHA DAS VADIAS DE GOIÂNIA/GO
}

\author{
Paula Nogueira Pires Batista*
}

RESUMO

O presente artigo busca apresentar e debater brevemente questões relacionadas a diferenças geracionais e a diferentes feminismos a partir de pesquisa etnográfica realizada durante os anos de 2014, 2015 e 2016 na Marcha das Vadias de Goiânia/GO. A partir dos dados de campo, há a busca por reflexões acerca de aspectos relacionados aos diferentes modos de conceber o corpo em protesto na Marcha das Vadias e os usos performáticos e políticos da nudez, interseccionados a marcadores sociais da diferença, a exemplo de gênero, sexualidade e idade/geração. Ademais, o artigo busca também pensar tanto rupturas e conflitos quanto as possibilidades de coalizão no campo feminista intergeracional.

Palavras-chave: Marcha das Vadias, jovens feministas, geração

"It's a matter of generation, I don't use my body that way": generational differences and different feminisms from Goiânia’s Slutwalk

\section{ABSTRACT}

The following paper seeks to present and debate briefly about questions concerning generational differences and the distinct feminisms based on etnographical research that happened during 2014, 2015 and 2016 in Goiânia's Slutwalk. There's a pursuit for reflections referenced on the field data about aspects related to the distinct ways of conceiving the body in protest situation at Slutwalk and the performatic and political uses of nudity, interseccionated with social markers of difference, for example gender, sexuality and age/generation. In addition, the paper also seeks to think about breaks and conflicts concerning the cohalition possibilites in the intergenerational feminist field.

Keywords: Slutwalk, young feminists, generation

"Es una cuestión de generación, yo no uso mi cuerpo así": Diferencias generacionales y diferentes feminismos a partir de la Marcha de las Putas de Goiânia/GO

\section{RESUMEN}

El presente artículo busca presentar y debatir brevemente cuestiones relacionadas a diferencias

* Mestra em Antropologia Social pela Universidade Federal de Goiás (PPGAS/UFG). E-mail: paulxnogueira@gmail.com 
generacionales y distintos feminismos a partir de la investigación etnográfica realizada durante los años 2014, 2015 y 2016 en la Marcha de las Putas de Goiânia/GO. A partir de los datos de campo, hay la búsqueda de reflexiones acerca de aspectos relacionados a los diferentes modos de concebir el cuerpo en protesta en la Marcha de las Putas y los usos performáticos y políticos de la desnudez, interseccionados a marcadores sociales de la diferencia, a ejemplo de género, sexualidad y edad/generación. Además, el artículo busca también pensar tanto las rupturas y conflictos como las posibilidades de coalición en el campo feminista intergeneracional.

\section{Palabras Clave: Marcha de las Putas, jóvenes feministas, generación}

Não é fácil, você sabe que essa relação geracional às vezes gera conflito, às vezes as jovens nos acham um pouco ultrapassadas, caretas, que não ousamos muito. A questão de usar o corpo é um limite que nós temos. Eu, por exemplo, eu tenho muito limite com a nudez. Tenho muito limite... Fui educada pra isso. Assim, sabe, aquele pudor... Então... tem um certo receio dessa exposição. Eu acho que, a minha geração, nós temos essa dificuldade. A grande maioria. Outras, talvez menos, né? Não sou ousada. Nesse sentido, é... Eu não uso meu corpo, assim, meu corpo nu. Eu uso de outras formas. Mas eu reconheço que é um bloqueio que nós temos. E que é uma questão de geração. [...] Mas eu acho [o termo] "vadia" ótimo. Porque o "vadias" rompe com os padrões. Rompe com a ideia da mulher “recatada". [...] Pareço ser certinha, mas não sou. Gostaria de ousar mais. Um dia eu vou ousar mais.[..] A minha preocupação é não cair no exibicionismo. Porque aí exibicionismo é outra coisa. Agora, se tem um monte de mulheres da minha geração e nós fazemos um [peitaço], como se fosse uma ala, todas com os corpos, nossos peitos caídos, nossas celulites expostas... [...] E a Marcha desse ano? Tá passando da hora. Bora organizar essa porra? E organizar umas velhinhas pra nós fazermos um peitaço? Eu vou botar fogo nas mais veinha. Anota meu número que eu anoto o seu. Paula de quê? Já sei, Paula vadia. [...] Já to com um conceito assim: a gente faz pra saída como se fosse uma ala das mais velhas fazendo peitaço... conduzindo! Porque a juventude não compreende isso, cara. Nós, mais velhas, conduzindo rapidamente, fazendo a abertura ali, com um peitaço. Nem precisa cartazes. Quando a gente faz peitaço, o corpo por si só fala. (Trecho adaptado de entrevista presencial com Izadora, caderno de campo, Goiânia, julho de 2016).

O trecho acima, retirado de meu caderno de campo, foi fruto de entrevista com a interlocutora Izadora ${ }^{1}, 68$ anos, que se considera negra, heterossexual e de classes médias. Como os demais trechos que aqui aparecerão, ele faz parte de entrevistas realizadas ao longo de minha pesquisa de mestrado sobre a Marcha das Vadias de Goiânia/GO (MdV/GO), no Brasil, durante os anos de 2014, 2015 e 2016², campo no qual eu mesma atuei como militante.

Um total de 16 entrevistas semiestruturadas foram realizadas presencialmente. Houve também conversas e encontros informais, além do acompanhamento de grupos on-line em redes sociais e plataformas virtuais que compuseram a pesquisa, a exemplo do Facebook ${ }^{3}$ e do Whatsapp $p^{4}$. Participaram das entrevistas tanto organizadoras das edições da MdV/GO quanto mulheres que participaram pontualmente dos atos. Ocasionalmente, diálogos com organizadoras e militantes da $\mathrm{MdV}$ em outras cidades brasileiras também contribuíram para as reflexões presentes, como é o caso de conversas com feministas do Rio de Janeiro/RJ, de Natal/ $\mathrm{RN}$ e de Florianópolis/SC. Além de encontros e reuniões pré-marcha, acompanhei os atos da

1 Todos os nomes das interlocutoras foram alterados, com o emprego do anonimato.

2 Parte das reflexões aqui presentes são frutos também dos debates realizados durante a 30a Reunião Brasileira de Antropologia, ocorrida entre os dias 03 e 06 de agosto de 2016, em João Pessoa/PB, no GT 40 - Marcadores sociais em diálogo: gênero, sexualidade, idade/geração e o curso da vida. Ele foi coordenado por Dr. Gustavo Santa Roza Saggese (Faculdade de Ciências Médicas da Santa Casa de São Paulo) e Dr. Raphael Bispo dos Santos (UFJF), com comentários de Dr. Carlos Eduardo Henning (UFG). Agradeço aos comentadores e participantes do GT pelas contribuições e reitero minha total responsabilidade autoral pelas questões aqui apresentadas. 
Marcha das Vadias de Goiânia/GO nos anos de 2014 e 2015 (não houve ato em 2016), além do ato em 2015 em Florianópolis/SC, onde realizei mobilidade acadêmica por meio do programa Procad/Casadinho UFSC/UFG.

Sendo eu também uma feminista jovem, com marcadores como bissexualidade, pertencimento às classes médias e cor branca, tal aproximação com o campo evidentemente trouxe implicações para a pesquisa e para a própria observação realizada. Não pretendo dar conta de todas essas consequências aqui, mas explorá-las na medida em que significam e são atravessadas por significados, pautando-me na reflexão de que um olhar de dentro é limitado e acessa determinados aspectos e não outros, assim como todos os pontos de vista também o são e o fazem. Coube à mim apenas tentar conferir e interpretar sentidos a esta posição ocupada.

Interessante dizer que, ainda que as Marchas das Vadias sejam consideradas expressões de “jovens feministas" e que de fato a maioria do público presente nos atos seja de pessoas que se consideram "jovens", Izadora, que é reconhecida como uma "feminista histórica" em Goiás ${ }^{5}$, participou da organização da primeira $\mathrm{MdV} / \mathrm{GO}$, em 2011, e esteve presente em outras edições, como na de 2015, quando nos encontramos pela primeira vez.

A fala no trecho destacado sublinha algumas das questões que surgiram em campo e que procurarei explorar neste artigo. De algum modo, elas trouxeram para debate aspectos relacionados a modos de conceber corpo, sexualidade e idade/ "geração", além de outros possíveis marcadores sociais da diferença, quando implicados no político - como é o caso de militâncias feministas.

As diferenças geracionais e os diferentes feminismos em jogo ganhariam, afinal, contornos interessantes quando pensados sob a ótica das chamadas performances geracionais (HENNING, 2014) e das performances de protesto (FUENTES, 2015), como proponho a seguir. A partir desse olhar atento, busco então possibilidades de entendimento circunscritas não apenas por rupturas e diferenças, mas também por potencialidades de alianças intergeracionais, que darão forma à complexidade do cenário feminista em questão. Não é por acaso, afinal, que Izadora termina esse trecho anotando meu telefone e convidando-me a construir com ela a próxima edição da MdV/GO.

\section{Marchas das Vadias, juventude e geração}

Situando transnacionalmente as Marchas das Vadias, ou Slutwalks, é importante compreender o contexto do seu surgimento: ocorrida no Canadá, em 2011, em reação à fala de um policial durante uma palestra sobre segurança pública, em um momento em que muitos casos de estupros no campus universitário eram relatados. $\mathrm{Na}$ ocasião da palestra, o policial afirmou que as mulheres não deveriam se vestir como vadias se não quisessem ser estupradas, culpabilizando as vítimas pela própria violência sofrida. Como reação, alunas e professoras da Osgode Hall organizaram a primeira Slutwalk, marchando com o corpo exposto e roupas supostamente "provocativas", além de cartazes, que contestavam a cultura do estupro e a ideia de que a culpa é da vítima (GOMES, SORJ, 2014).

Segundo observações e relatos de interlocutoras em campo, a primeira Marcha das Vadias goiana aconteceu no ano de 2011, na cidade de Goiás, durante o XIII Festival Internacional de Cinema Ambiental (FICA). Ela foi organizada por militantes ligadas ao Fórum

3 Trago o Facebook como rede social on-line, na qual é possível criar e adentrar grupos de discussões e eventos de interesse, compreendendo as Marchas das Vadias como eventos organizados e divulgados, na maioria das cidades observadas, a partir também dessa rede. Em meu trabalho de campo, foi imprescindível que eu adentrasse grupos on-line, tanto em Goiânia/GO quanto em Florianópolis/SC, para ter acesso às discussões.

4 O Whatsapp Messenger é um aplicativo de mensagens multiplataforma que permite a troca de mensagens entre celulares do tipo smartphones, tablets, notebooks, entre outros aparelhos, sem custos adicionais, apenas com o uso de tecnologia 3G/4G ou rede de internet sem fio, o que torna a comunicação mais rápida, ágil e barata entre pessoas que disponham de tal acesso.

5 O termo advém de sua participação em momentos feministas históricos na cidade, como na fundação do Fórum Goiano de Mulheres, na década de 1990. Em campo, observei que tanto a interlocutora quanto outras feministas utilizavam o termo para se referirem a Izadora. 
Goiano de Mulheres (FGM), considerado por muitas interlocutoras um dos espaços feministas mais importantes na cidade, com atuação desde a década de 1990. Entre as organizadoras dessa primeira marcha em 2011 estava Izadora, que por sinal também é uma das fundadoras do Fórum.

Ao reler meu caderno de campo, um trecho que relata meu encontro com Izadora em julho de 2016 mostra-se particularmente interessante para pensar as possibilidades de pontes, alianças e encontros geracionais. Trata-se do trecho que narra o meu encontro com ela e com a interlocutora Maria, 33 anos, que se considera bissexual, "parda" e de classes médias, ocorrido no Ponto 18, um dos bares gay friendly mais antigos da cidade (BRAZ, 2014).

Naquele sábado, Maria, amiga militante da marcha e também interlocutora da pesquisa, havia me indicado para fazer uma palestra sobre sexismo e cultura do estupro. Após a palestra, na qual Maria estava, marcamos de nos encontrar no Ponto 18 para tomarmos uma cerveja e conversarmos. $\mathrm{Na}$ verdade, eu já estava voltando para casa, porque não tinha almoçado e estava com fome, mas Maria me ligou no meio do caminho. Sugeri então que nos encontrássemos no Ponto 18, que ficava a algumas quadras do Instituto. Este era o mesmo bar, no centro de Goiânia, conhecido das antigas por ser gay friendly e no qual eu já havia entrevistado Lana. Cheguei lá sozinha e encontrei duas mulheres organizando mesas na calçada. O bar devia ter acabado de abrir. Uma delas, por mim desconhecida, era uma moça negra, baixinha e de cabelos cacheados, que me cumprimentou com uma piscadela de olho e um sorriso, ao qual eu retribuí. Parecia uma cantada. A outra, mais velha, era Izadora. Eu lembrava de Izadora da MdV/GO de 2015, quando dividimos um taxi na volta, junto com Maria, e esta a apresentou como uma das feministas históricas de Goiás. Mas eu não estava certa de que ela se lembraria de mim. Por timidez e receio de ser inconveniente, preferi sentar na parte de dentro do bar e esperar Maria chegar, já que com certeza Maria puxaria assunto com ambas e poderia fazer uma ponte melhor entre nós (como já havia feito em 2015). Ali, já imaginei que abriríamos um diálogo sobre a marcha. Poucos minutos depois, logo na chegada, Maria lhes abraçou e me chamou. Contou a elas da palestra e mencionou minha pesquisa, à qual Izadora se dispôs de imediato a colaborar e contar como havia participado da organização da primeira MdV goiana (Trecho adaptado de caderno de campo, Goiânia, julho de 2016).

Penso ser curioso que diante de minha timidez e receio em abordar Izadora, "um nome feminista histórico e importante em Goiás", eu tenha esperado por Maria, de geração posterior à minha, mas anterior à de Izadora, para que a tal "ponte" pudesse ser feita. Interessante citar também que em um outro momento, quando nos reuníamos para um protesto em Brasília, tentei abordar uma outra feminista histórica na cidade, também fundadora do Fórum Goiano, Luciléia, que iria ao ato no mesmo ônibus em que eu estava, e recebi uma resposta bastante seca e desinteressada ao mencionar a pesquisa - a qual não sei se teria sido a mesma caso uma outra ponte e apresentação, como a de Maria, houvesse sido feita.

Durante a entrevista com Izadora, ela ressaltou que, apesar de ter sido uma das fundadoras do Fórum Goiano de Mulheres, não atuava nele mais - por razões relacionadas inclusive ao que ela mencionou como "conflitos geracionais" com outras militantes. Interessante notar que, como seria narrado posteriormente em campo, após a segunda edição da Marcha das Vadias em Goiânia, houve a decisão de "desvinculá-la" do FGM, sob um argumento que, creio, possa ser pensado sob diversas perspectivas - incluindo também a geracional e as diferentes visões dos feminismos.

Neste ponto da conversa, Maria apontou, em um tom animado, que a partir de 2012 "as novinhas teriam tomado conta". Conforme conversávamos, pude perceber que, desde o início, na primeira edição da Marcha das Vadias goiana, houve uma associação entre a MdV em Goiás e um "público jovem", como presente no trecho da conversa com Izadora:

Eu tive a ideia, vamo fazer no Fica? Dentro do Fica? Lá a gente tem público garantido. (...) Convenci o pessoal de que seria interessante fazer no Fica. Aproveitar o público do Fica, porque o Fica tem um público extremamente irreverente, muito jovem, muita gente de esquerda, muita gente que 
compreende essa luta, e que poderia entender e somar conosco. Então vamos. [...] Porque o apoio lá... é claro que teve gente que torceu o nariz, mas ali, quem domina o Fica é a juventude. (Trecho adaptado de entrevista presencial, caderno de campo, Goiânia, julho de 2016. Grifos meus)

No decorrer do diálogo, em diversos momentos da fala de Izadora, pude perceber como ela tomava a ideia das feministas históricas como sendo estas detentoras de um "saber maior", "fruto de mais experiência" e que mereceriam respeitabilidade pelas mais jovens - o que nem sempre acontecia, na sua opinião, gerando o que ela interpretou como "casos de desrespeito", aos quais ela demonstraria bastante ressentimento.

Por outro lado, o modo como Izadora se referia à juventude e às jovens feministas mostrava ânimo, entusiasmo, como se saudasse as jovens militantes e enxergasse ali possibilidades não apenas de alianças, mas principalmente de continuidades - embora essas não fossem exatamente lineares ou sem contradições. As contradições inclusive apareceram em sua fala alusiva a um conflito com a militante Laura, de 35 anos à época da pesquisa, e a qual Izadora teria tomado como uma filha no feminismo. Segundo seu relato, esse conflito seria parte importante de sua saída do Fórum Goiano de Mulheres.

Antes de narrar o que pude escutar de sua versão do conflito, interessa-me pensar um pouco sobre o que se diz em referência a "geração". Sobre o conceito de "geração", o sociólogo húngaro Karl Mannhein (1982), no texto original de 1927, afirmou que ela poderia ser compreendida a partir do compartilhamento, na juventude de indivíduos de idades semelhantes, de uma situação social e histórica em comum, sendo assim uma espécie de posição social. Como aponta o sociólogo brasileiro Luiz Antônio Groppo (2015), Mannhein daria início à “desnaturalização" do que se conceberia até então enquanto juventude.

Apesar de um fundo ainda naturalista, $\mathrm{o}$ autor ressalta que insere Mannhein no grupo chamado de "teorias críticas da juventude" porque este enfatiza o seu potencial transformador em relação a gerações anteriores, distinguindo-se assim das chamadas "teorias tradicionais da juventude". Tais "teorias tradicionais" colocariam em foco uma visão estrutural-funcionalista, na qual seria função da juventude uma socialização secundária, expondo portanto o jovem a riscos de "anormalidade" e desvio. Já as "teorias críticas" seriam importantes na segunda metade do século XX por questionarem essa vinculação demasiadamente determinista dos indivíduos à estrutura social. Todavia, a noção de socialização secundária permaneceria (GROPPO, 2015, p. 5).

Para Groppo (2015, p. 9), a ideia de potencial renovador da sociedade contido na juventude seria uma importante contribuição de Mannhein no ideal de desenvolvimento humano da modernidade. Enquanto o jovem estaria em uma fase de experimentação de seus quadros de referência e valores, os adultos já os teriam mais solidificados, o que os tornariam mais resistentes a mudanças. Seriam ainda as "teorias críticas" a darem início ao reconhecimento das diferentes percepções de vivências da juventude, considerando marcadores como classe social, gênero, etnia e nacionalidade - noções essas que seriam radicalizadas nas teorias pós-críticas, que relativizariam e chegariam mesmo a negar a ideia de juventude como "transição" para a fase adulta nessa socialização secundária (GROPPO, 2015, p. 27).

Dito isso, interessa-me pensar aqui na ideia de geração interseccionada a demais marcadores sociais da diferença, o que possibilita certa análise do campo. Busco refletir sobre como essas intersecções por vezes serão ganchos para rupturas, outras vezes para continuidades, dando forma à complexidade do cenário feminista em questão.São entre conflitose articulações em torno de interesses em comum que as falas caminharão, demonstrando $\mathrm{o}$ aspecto enriquecedor $\mathrm{e}$ desafiador da existência de feminismos, no plural. Isso ficará nítido nas narrativas apresentadas por interlocutoras ao longo da pesquisa, inclusive nas disputas discursivas em torno do ato de "desvinculação" da MdV ao Fórum Goiano de Mulheres. Afinal, ao lado da "feminista histórica" Izadora na construção da primeira Marcha das Vadias goiana, estava também Laura, de geração posterior à sua. Laura se considera mestiça, bissexual e de classes trabalhadoras. Relevante dizer que Laura também foi coordenadora do Fórum, pedindo afastamento deste em 2014, ano 
em que, segundo ela, "as coisas degringolaram e houve um esvaziamento" (Fala de interlocutora, entrevista presencial, Goiânia, março de 2017).

Sobre diferentes razões para a "desvinculação" da Marcha das Vadias do Fórum Goiano, a interlocutora Maria apresentou outras perspectivas para além das geracionais. Segundo ela, não teria havido uma "desvinculação", mas sim um "desdobramento", necessário sob sua ótica por questões de burocracia. "Não foi criado o coletivo [Marcha das Vadias]. Foi tudo uma questão de burocracia, pra colocar no ofício [a ser encaminhado às autoridades estatais para realização do ato, como na comunicação à Polícia Militar]" (Fala de interlocutora, entrevista presencial, Goiânia, 2017). Nesse ponto, uma das diferenças entre as organizações que me chamou atenção ao acompanhar reuniões pré-ato da $\mathrm{MdV}$ de Florianópolis/SC foi a decisão deliberada das organizadoras de não enviar comunicados prévios ao Estado, considerando a orientação política anarquista da maioria das militantes.

\section{Diferenças geracionais e diferentes feminismos em jogo}

Quando eu estava na mesa do Ponto 18 com Izadora e Maria, Izadora relataria um conflito com Laura durante a organização da primeira $\mathrm{MdV}$, a ser realizada na cidade de Goiás, no FICA. Segundo seu relato, Laura iria de carro buscar Izadora. Antes, estaria encarregada de algumas tarefas, como comprar materiais para a confecção de cartazes, buscar megafones, entre outras atividades preparatórias para o ato. Combinaram de se encontrar em um determinado horário, na casa de Izadora, mas Laura se atrasou, o que acabou por gerar um atrito entre elas e irritar Izadora profundamente. Todavia, na fala da interlocutora histórica, chamou-me atenção as associações que Izadora fez entre tal conflito, exercício da sexualidade, modos de conceber militância, juventude e questões geracionais.

Pô, cara, eu tenho muitos anos de militância. Encaminhamento é encaminhamento. Tem que cumprir! Se não vai cumprir, não assume o compromisso. É militante, tem que cumprir! Você divide tarefa, tem que cumprir, sabe? É imperdoável você não cumprir uma tarefa. Tarefa é tarefa! Mas... a Laura não chegava. Ela chegou eram umas seis horas. Cara emburrada. Aí eu desci com minha bagagem, a mochila... [...]. Falei "ah, Laura, que atraso, pô.' Mas ela 'não, mas dá tempo, preocupa não'. Aí tá, botei as coisas no porta-malas, entrei no carro, e falei assim: 'mas você pegou os textos, né?'. "Não". "Você comprou as cartolinas?'. "Não". "Nem os pincéis?" "Não". "Você pegou os megafones?" "Não". Falei "pô, cara... Nossa, Laura, não fez nada que ficou de você fazer?". "Fiz não, não fiz.. Falei Laura, porra cara, aí é foda, né bicho? Não pode ser assim. Por que tu não fez? E agora? Cartolina a gente até compra em Goiás, mas os megafones, cara... Olha o tanto de gente que ainda temos que buscar. E nós queríamos chegar com antecedência para assistirmos ao show da Maria Rita. E aí eu falei! Eu tinha o direito de reclamar. Mas não fui grosseira com ela, só falei "pô, cara, mas porra!". A Laura é da minha casa, eu usava toda essa linguagem com ela. Ela "eu não fui mesmo não, não adianta você achar ruim". Falei "Ué, o que tá acontecendo?". Ela disse "eu fui fazer sexo. Se eu não fizesse sexo eu não dava conta nem de dirigir e chegar até em Goiás.” NOSSA!!! Mas aquilo me deu uma raiva TÃO grande! Aí eu respirei e pensei "eu não posso dizer que ela não podia fazer sexo". Mas ela podia ter sido honesta! Mas devia ter jogado limpo. E ela falou num cinismo, foi cínica, sabe? Esnobou. E eu engasgada com essa moça... nós chegamos em Goiás não sei nem que hora. Chegamos em Goiás, fizemos a marcha. [...] Acabou a marcha, fomos pra casa. Aí ela tocou no assunto. E com deboche. Aí EU falei “Ô Laura, eu não tenho problema nenhum de você ter ido fazer sexo. Você tá achando que eu nunca fiz sexo, Laura? Eu sou um mulher de - falei lá minha idade, não sei nem quantos anos eu tinha, véia pra cacete, mas tudo bem. Eu já tenho 68. Mas você tinha que ter sido honesta. [...] Aí eu falei pra ela 'Laura, sabe o que acontece? Eu não sei com as outras, mas comigo, acho que nós estamos chegando num momento em que acho que nós temos que separar a militância por geração. Porque você tem 30 anos, tá no auge da tua sexualidade, ninguém pode te reprimir. Porque eu quando tinha a tua idade eu também tava desse jeito. É um direito que você tem. Nós, mulheres mais maduras, nós já estamos com a libido comprometida, assim... a gente já tá fazendo militância, não estamos correndo atrás de sexo. Por 
uma questão de idade. $\mathrm{O}$ dia que você tiver nossa idade, 60 anos, 60 e pouco, você vai saber o que é libido. Porque cada uma tem a sua fase." (Entrevista presencial com Izadora, caderno de campo, Goiânia, julho de 2016. Grifos meus)

No relato apresentado, aspectos da própria formação militante de Izadora podem ser observados. A ideia de que "é imperdoável não cumprir uma tarefa" remete a uma formação mais rígida, alusiva a um período histórico de dura repressão, como foi o da ditadura militar brasileira, vivida pela interlocutora em sua juventude. No período ditatorial, em nome de uma suposta defesa da ordem nacional contra aquilo que se nomeava enquanto "guerra revolucionária comunista", o Estado brasileiro se apoiou nas Forças Armadas, que utilizou o discurso da segurança nacional para reprimir toda a sorte de direitos democráticos - inclusive a de livre manifestação e expressão. Conforme Izadora relata, ela conheceria o feminismo nos anos 1960 e 1970 a partir de referências dos Estados Unidos e na Europa, mas entenderia tudo aquilo como muito distante de sua realidade, especialmente em Goiás.

Em determinado momento de nossa entrevista, Izadora se define como "geração Ditadura Militar", ainda que sua atuação como feminista tenha se dado dos anos $1990 \mathrm{em}$ diante. Contudo, ela reconhece o impacto que ser "geração ditadura" teve em sua militância, mesmo em momentos distintos, como nos anos 1980, considerando sua atuação sindicalista e na luta pela educação. Além disso, a interlocutora aponta a necessidade de "endurecer" para se fazer ouvida enquanto mulher na militância partidária e sindicalista, cenário dominado por homens. "O tanto que você imaginar a dureza, multiplique muitas vezes. É muito sofrido" (Entrevista presencial com Izadora, caderno de campo, Goiânia, julho de 2016).

Ao traçar uma narrativa sobre a resistência feminista goiana no cenário ditatorial, a historiadora Rúbia Rodrigues (2010) traz entrevista, realizada em dezembro de 2009, com a socióloga feminista Nilva Maria Gomes Coêlho, também uma "feminista histórica" goiana. A socióloga foi presidente do Diretório Acadêmico da Universidade Federal de Goiás, e presa e torturada pelos militares em Goiânia durante a ditadura, com memórias sobre aquilo que mais a marcou em sua prisão. Seu relato traz o modo como a nudez foi instrumentalizada nos atos de tortura, bem como a interpretação que isso assume diante dos valores morais vigentes, ao lado da noção de que "mulheres que lutavam contra a repressão eram lidas como putas pelos agentes da violência”. O corpo assume então centralidade nos relatos de memória da violência (JELIN, 2001), inclusive no que tange à sua nudez, com sentidos próprios com relação aos corpos das mulheres (COLLING, 1997).

[...] me marcou isso e o sequestro, porque eu estava indo para um noivado e nós estávamos pensando que estávamos livres [...]. Já foram colocando capuz na gente, igual cena de filme. [...] Porque eu acho que o que me assusta é essa questão do sequestro e dos valores morais, porque a gente tem que se despir quando a gente nunca se despiu na frente de ninguém e é ensinada a se cobrir. [...] É o que eu digo pra você, todos foram torturados? Foram, simbolicamente, porque simbolicamente isso aqui é simbolicamente não, é uma ação que eu estou participando com meu corpo, mas é simbólica, não é física. Eu estou dizendo a você, não sei o que é pior, porque a outra arrebenta, receber um choque na vagina e na orelha ao mesmo tempo quem aguenta? [...] e pra mulher acho que é a coisa mais difícil foi essa, porque você é criada com um valor né, feminista, chega lá, você quer depor vestida ou nua? Você quer com os olhos abertos ou fechados? É lógico que eu quero aberto e se é pra tirar a roupa, eu quero te encarar e isso uma turma fez de mulheres. Quer dizer, a gente rebentada e agora ainda tem que tirar a roupa de baixo de um capuz não dá, quer dizer, se deram a opção. [...] isso é muito difícil, porque você é criada para nunca um homem pegar no seu corpo, nunca transou, nunca não sei o que, aí eu digo: será que valeu a pena ficar 24, 25 anos sem transar? E isso foi pior que transar. Uma tortura dessa, vai tirando a roupa pra um estranho, quer dizer, que valores morais são esses? Você hoje fica despida na frente de uma mulher, nós não! Foi na frente de homem mesmo. Em questão de mulher eles queriam saber porque a mulher que tava nisso era o que? Puta, quer dizer, não merecia nem o respeito. [...] e aí, foi que ficou claro, pra mim ficou muito claro a questão, porque a luta política 
não ficava só em política, tinha umas questões que tinha que lutar mesmo porque a mulher precisa disso (RODRIGUES, 2010, p. 82).

O próprio cenário de constituição do Fórum Goiano de Mulheres é interessante para pensar as relações geracionais entre feministas. Fundado na década de 1990 por "feministas históricas" goianas, ele surge em um contexto de preparação para a Conferência Mundial de Mulheres em Beijing, na China, e se torna um importante lugar de reunião das mais variadas expressões feministas, aglutinando tanto feministas autônomas quanto partidárias - embora, é claro, não sem conflitos ou "rachas" internos. Como disse Maria em uma conversa, "o Fórum representa o feminismo de um tempo, de uma época. Ele representa a formatação do feminismo em 1990. A pluralidade e diversidade inclusive em 90. (...) Ele articula e desarticula conforme o próprio caminhar do movimento" (Entrevista com interlocutora por Whatsapp, Goiânia, maio de 2016). Nacionalmente, o FGM se conecta com a Articulação de Mulheres Brasileiras (AMB) e segue sua carta de princípios e política geral. Izadora, por exemplo, é uma feminista que se articula politicamente de forma partidária. Contudo, a carta de princípios do FGM ressalta o seu caráter apartidário ${ }^{6}$.

Situando historicamente os cenários feministas em contexto brasileiro, Ana Alice Alcântara Costa (2006) identifica a década de 1990 como um momento de fragilidade e precarização, especialmente dos conselhos e organismos de governo para mulheres, os quais se encontravam desprestigiados. Foi neste contexto que muitas feministas, várias delas inseridas nos órgãos dos anos 1980, criaram organizações não-governamentais. Sônia Álvarez (1998, 1999) aborda o processo de "ONGização" do movimento feminista - que não remete exatamente à proliferação de ONGs, mas a uma "promoção ativa e sancionamento oficial pelo neoliberalismo nacional e global de determinados formatos e práticas organizativas entre organizações feministas e outros setores da sociedade civil" (ÁLVAREZ, 2014, p. 27).

Ao colocar a ideia de "separar a militância por geração", com base em um conflito que, a princípio e na visão de Izadora, envolveria questões associadas aos modos de conceber não apenas a militância, mas a temporalidade, a sexualidade e o seu exercício, a interlocutora parece também reforçar estereótipos de fundos naturalistas, como se a velhice significasse um declínio da sexualidade e da libido - questões já questionadas e problematizadas, por exemplo, na teoria antropológica ${ }^{7}$.

Todavia, para a interlocutora Laura, não era disso que se tratava o conflito, mas de questões emocionais, de mágoas anteriores, que envolveriam também o seu cansaço diante do "autoritarismo" de Izadora, com o qual Laura haveria "explodido" naquela situação. Novamente, uma interpretação que alude a diferenças geracionais, presente inclusive em relações familiares. Aqui, os papéis de "mãe" e "filha" política também parecem estar presentes, a imagem de Laura sendo interpretada por ela mesma como a de "filha rebelde".

Como eu comecei o feminismo vinculada a ela, ela me tem no momento como se eu fosse uma filha injusta, uma filha rebelde, que não deu valor... E aí ela fez coisas interessantes. Em 2014, eu fui eleita coordenadora nacional. Um rolê que as mulheres de Goiás não conseguiram entender. A minha organização nacional não se organiza por delegadas por Estado. É horizontal. São nove frentes. Tudo acontece paralelo. Mas para ajudar a tocar, havia a figura da coordenação. Cinco coordenadoras. E essas mulheres eram eleitas por aclamação. Em 2014, eu fui convidada pelas mulheres de Recife. $\mathrm{E}$ as mulheres de Goiás não entenderam isso. (...) A partir do momento que eu assumi, algumas mulheres aqui de Goiás, que tinham interesses políticos dentro do Fórum... nossa política de autonomia estava incomodando um grupo. E por outro lado, tinham essas mágoas... De modo que na plenária de Brasília, foi um grupo de mulheres,

6 Disponível em: https://www.facebook.com/pg/AMB.FGM/about/?entry_point=page_nav_about_item\&ref=page_internal. Acesso em: 12 fev. 2017.

7 Sobre velhice, gênero e sexualidade, ver Debert \& Brigeiro, 2012; Debert \& Henning, 2015, Debert, Simões \& Henning, 2016. 
inclusive a Izadora, falar horrores de mim. (...) Que eu tinha viajado pra Argentina com o dinheiro da prefeitura. Eu nunca nem fui pra Argentina! Fizeram acusações muito más, levianas, que eu era racista... porque não entenderam. Mas isso é secundário, é pequena política, e ainda atravanca as coisas aqui em Goiás (Entrevista presencial com Laura. Caderno de campo, Goiânia, março de 2017. Grifos meus).

Interessante pensar ainda como Laura interpreta a situação conflituosa: se para Izadora, sexualidade eirresponsabilidade no cumprimento de tarefas surgem como aspectos centrais no desentendimento, Laura aciona elementos relacionados a outras mágoas e interesses políticos. Todavia, ainda que esses interesses não envolvam modos de conceber sexualidade, por exemplo, ainda assim acionam elementos de uma certa insubordinação geracional.

Aqui, penso que a ideia de "filha política" aciona um aspecto geracional relevante - como se os filhos se tornassem rebeldes ao contrariar as decisões dos pais, quebrando suas expectativas, um ruído na transmissão geracional. Nesse sentido, Laura também assume a posição da "jovem rebelde", que contrariou uma geração anterior. Sobre essa ideia de transmissão geracional, é interessante problematizar as possibilidades de leitura que assumem uma via de mão única - como se o ensinar se desse apenas em um sentido, das mais velhas para as mais novas, descartando que as "filhas" também teriam algo a ensinar a essas "mães", entendendo que o aprendizado é uma via de mão dupla.

A ideia metafórica de "mãe" e "filha" políticas foi aqui relatada na tentativa de observar se não poderia haver uma "expectativa frustrada" de algumas feministas mais velhas para com as mais jovens, como se fosse esperado um ciclo relativamente fechado e contínuo, que não desse abertura para desdobramentos, inclusive políticos, inesperados. O papel da "filha política" seria assumir o lugar da mãe, um lugar de continuidade de sua política diretamente atravessada por relações de poder, sem muita abertura para que nesse processo novas experiências e decisões fossem tomadas.

Em todo caso, essa é uma perspectiva contraditória que pode ser observada na própria
Marchas das Vadias de Goiânia, com jovens feministas usando os corpos de modos distintos daqueles concebidos por feministas mais velhas em suas performances de protesto e, por um lado, sendo saudadas e recebendo as boas vindas, enquanto por outro, não contando com a presença das mais velhas nos atos.

Embora o conflito tenha sido o tônus desse relato, penso que seja desejável ressaltar as contradições que permeiam a vida política: como em qualquer âmbito humano, não se vive só de continuidades ou só de rupturas. As alianças feitas até então foram mais do que frutíferas para as militâncias feministas colocadas em perspectiva, como mostra a própria experiência de Izadora e Laura organizando juntas a primeira MdV/GO. Afinal, apesar dos problemas, a marcha aconteceu e teve seus efeitos políticos. Novamente, que os feminismos sejam múltiplos não se traduz necessariamente em um problema, mas que as possibilidades de aglutinação e alinhamento de agendas sejam compreendidas nos seus momentos políticos importantes é uma busca que se mostra relevante nas estratégias de coalizão, inclusive transnacionais.

Nas linhas que seguem, continuo as análises pautando diferente visões, atravessadas por diferentes marcadores, que refletem inclusive sobre o uso do nome "Vadias" - que mostrou não ser consenso nos variados espaços feministas, principalmente entre feministas negras - e problematizam os diferentes usos dos corpos em campo. Aqui, um aspecto interessante da marcha goiana merece ser apresentado: no ano de 2014, houve a mudança do nome "Marcha das Vadias de Goiânia" para "Marcha das Libertas", baseada na crítica advinda principalmente de feministas negras de Brasília.

Segundo relatos de campo, o termo seria problemático principalmente pelas possibilidades de uma leitura "hiperssexualizada" (termo êmico) de corpos negros. Para as mulheres negras que criticavam tal uso, o termo "vadia" teria um peso diferente, considerando um cenário histórico de escravidão, racismo, violência e leitura desses corpos, que não lhes representaria. Após a crítica advinda principalmente da militante goiana Glória, de 33 anos, que se considera lésbica, de classes médias e não-branca, foi realizada a mudança para o nome "Marcha das Libertas" 
- mudança esta que não foi exatamente um consenso entre todas as militantes.

Contudo, em 2015, foram outras feministas negras em Goiânia, que passaram a fazer parte da organização, que reivindicaram o retorno ao nome "Marcha das Vadias". Tal retorno se deu sob argumentos, por exemplo, de que a mera mudança do nome não significaria uma abordagem adequada da discussão racial e que ela inclusive poderia gerar consequências indesejáveis, como o esvaziamento e a falta de visibilidade da marcha, percebidas em 2014.

\section{"Somos todas vadias"?}

Um fato que me chamou atenção foi que Izadora não só demonstrou gostar, como defendeu o nome "vadias", recusando sua mudança para "libertas", em nova nomeação à marcha. "Quiseram mudar o nome, a gente não aceita, é vadias! Não é libertas, não, é vadias!”, ela me disse. Por outro lado, a sua ideia do corpo em ativismo, incluindo o uso performático da nudez, como realizado pelas $\mathrm{MdVs}$, demonstrou uma associação direta com questões que ela entende como geracionais - e que é atravessada por aspectos morais. Para ela, "usar o corpo [nu] é um limite que nós temos", limite associado diretamente à sua geração.

Em relação aos usos dos corpos em ativismo, a visão de Izadora será corroborada pela interlocutora Ana, 42 anos, feminista, que se considera branca, de classes médias altas e mãe de duas jovens feministas. Entre suas filhas está Júlia, 23, branca, de classes médias, universitária e bissexual e que, ao contrário de Ana, já participou da marcha e defende o uso performático da nudez enquanto ferramenta de protesto: "é preciso confrontar! E se há esse choque, é porque está dando certo" (Entrevista por Whatsapp com interlocutora, caderno de campo, Goiânia, julho de 2016).

De acordo com os relatos de Ana, assim como sua mãe e sua vó, ela sempre foi feminista - só não sabia que existia um termo que designasse suas práticas. Aprendeu então a usar o termo com suas filhas. Ana diz entender o uso dos corpos nus e semi-nus, mas discordar desse uso. Ela também aciona aspectos geracionais, além daqueles de classe, para explicar a sua discordância.

Um movimento desses não me representa. Eu não usaria o corpo dessa forma. Eu sou de uma geração que cresci ouvindo a minha vó e a minha mãe dizerem assim, que o homem senta no chão, levanta, sacode a poeira da bunda e vai embora. A mulher quando ela vai e senta no chão, mancha a bunda. Não adianta sacudir a poeira porque a mancha fica lá. Entendeu? E ao mesmo tempo que eu ouvi minha mãe e minha avó dizerem isso, eu ouvi elas dizendo assim que quando se tem dinheiro, a mancha sai, entendeu? Olha só... a noção que elas já tinham, sabe? (...) Mas com as minhas filhas, eu acho que consegui reformular isso. Desde que a gente começou a conversar sobre sexo, eu falei aqui em casa: lavou, tá novo (Conversa por áudio no Whatsapp com Ana, Goiânia, junho de 2016)

Não por acaso, apresentei aqui falas de mãe e filha feministas, porque a ideia de "minha mãe não entende a marcha" surgiu com frequência em campo entre os relatos das jovens feministas. Os conflitos poderiam ser associados principalmente às interpretações dos usos performáticos dos corpos nus e à nomeação da marcha. Além disso, há ainda o fato de que eu mesma, enquanto jovem feminista e pesquisadora, encontrei conflitos com meus próprios pais ao decidir militar e estudar a MdV. Lembro, por exemplo, de na véspera da Marcha das Vadias de Florianópolis, em 2015, receber a seguinte mensagem de minha mãe: "vê se não vai protestar de lingerie na rua". Na ocasião, acionei a "obediência rebelde": obedeci e protestei sem lingerie, fazendo o chamado "peitaço", um dos usos políticos feministas performáticos da nudez.

No que tange à nudez enquanto ferramenta performática de protesto, a interlocutora Laura demonstrou gostar da ideia de "expor o corpo" enquanto protesto. Para ela, as contestações quanto a isso refletiriam certo moralismo. Já a interlocutora e organizadora da MdV/GO Emma, 25 anos, branca, lésbica e de classes populares, quando questionada a respeito do uso da nudez, colocou sua classe social como um aspecto forte que atravessaria sua subjetividade. Durante todo o campo pude notar que Emma não participou dos "peitaços" ou mesmo usou lingeries.

Para ela, usar roupas largas, que não 
marcassem seu corpo, seria uma estratégia de sobrevivência ao longo de sua vida, considerando as várias tentativas de estupro pelas quais passou. Sendo assim, de acordo com suas falas, não faria sentido tirar a roupa na $\mathrm{MdV}$, se no ônibus de volta para casa ela não poderia fazer a mesma coisa, o que provavelmente seria interpretado como exposição desnecessária e correria o risco de receber uma resposta equivocada por parte dos homens, que poderia inclusive tornar-se sinônimo de violências.

Todavia, a forma como Emma coloca a questão poderia dar a entender que a culpa da violência sexual é da roupa - o que ela tem como nítido que não é. Mas isso não significa que a roupa, ou a ausência dela, não acione significados imaginados e atribuídos por uma cultura sexista e de estupro, na qual ela poderia - e provavelmente iria - sair prejudicada. Afinal, conforme suas próprias palavras, Emma equaciona sua expressão corporal e de feminilidade de seguinte forma: "quanto mais invisível eu for, maiores as chances de eu continuar viva" (Caderno de campo, Goiânia, 2016).

Ao mesmo tempo, durante nossa conversa, Emma apontou como sua experiência é subjetiva e não refletirá a percepção de todas as jovens periféricas. Ela será inclusive uma minoria, considerada "hippie" em sua vizinhança, na qual as meninas gostam de shortinho e de tops. Ainda que ela associe em determinado momento a ideia de usar essas roupas com a noção de que "acho que não caiu a ficha para essas meninas", acaba por concluir que, afinal, usar muita roupa ou usar pouca roupa são duas formas - mais semelhantes do que a princípio parecem - de encarar a mesma questão:

Então eu acho que mostrar essa corporalidade toda tem uma ligação com o que social pede pras meninas, e aí as minas que não querem mostrar o corpo acionam essa coisa da feminilidade, que não querem ter e não querem usar, acionam os abusos em suas trajetórias... e as minas que mostram, algumas, também acionam tudo isso. Que é pra tentar ir contra, que é tipo, eu tenho amigas que fazem isso. São combatentes e usam uma corporalidade não hegemônica, então elas querem derrubar. O que acontece é: pra mostrar o corpo ou não, as minas vão acionar as mesmas coisas! Só que umas pra derrubar e outras pra.. todas elas lutando contra, mas umas tentando não mexer com isso, porque é violentador e traumático e a resistência delas construída foi essa, e as outras, porque elas querem quebrar de uma outra forma, que é chocando mesmo e querendo abrir assim "olha, eu to tirando aqui pra que todo mundo possa tirar num ônibus". Mas poderia ter a ver com essa consciência da violência (Fala de Emma, caderno de campo, entrevista presencial, Goiânia, novembro de 2016, grifos meus).

A seguir, ao buscar interpretar as "performances geracionais" (HENNING, 2014) e as "performances de protesto" (FUENTES, 2015) em campo, continuo a análise sobre como diferentes corpos, marcados de formas distintas, buscarão atuações militantes diferentes, e como isso se refletirá no político. Tal reflexo por vezes poderá decorrer em conflitos, mas isso não significa que a existência deles não possa ser ela mesma enriquecedora e com desdobramentos frutíferos capazes de gerar, inclusive, possibilidades de coalizões.

\section{Performances Geracionais Performances de Protesto}

Entre as organizadoras da MdV/GO 2015 com as quais tive contato, um outro relato associado a debates sobre geração em meu campo foi especialmente interessante. Entre conversas informais, percebi uma tensão geracional em relação às "feministas históricas", principalmente as que compõem o Fórum Goiano de Mulheres, cuja atuação é fundamental para pensar as práticas e políticas feministas em Goiás. Tais tensões estariam principalmente relacionadas às formas políticas de atuação.

Para algumas, a organização pautada por aspectos como "horizontalidade" e "autogestão" - isto é, vista como sem hierarquias, baseada na ideia do "faça você mesma" e auxiliada pelas redes sociais e mídias digitais - "não dialogaria com essas feministas". Haveria mesmo a fala de que "elas não se sentiram convidadas porque não enviamos um convite formal. Evento no Facebook para elas não conta" (Caderno de campo, conversa presencial com interlocutora, Goiânia, agosto de 2015). Nessa visão, mesmo 
aquelas que eventualmente comparecessem à marcha, ainda se pautariam por noções de militância e por aquilo que Fuentes (2015) chama de "performances de protesto" associadas ao partidarismo - como a fala em palanque, no microfone. Sobre as performances de protesto, a autora afirma que:

A relação entre a performance e a política dá forma a uma grande gama de comportamentos, sujeitos e agentes, abrangendo desde os corpos individuais aos corpos de protesto. (...) As performances de protesto também levantam a questão do valor e da eficácia de eventos simbólicos corporais, tanto online quanto off-line. (...) Levar protestos performáticos a sério, mesmo que seus resultados a longo prazo não possam ser imediatamente discernidos, nos permite explorar subjetividades políticas contemporâneas (nem todas necessariamente progressistas) e as maneiras em que a relação entre ação humana e política está sendo redefinida nos contextos póscoloniais, neoliberais, e neoconservadores, com sistemas e legados de opressão e resistência que sobrepõem-se (sic) uns aos outros. (FUENTES, 2015, s-p).

Emma relataria, por exemplo, acreditar que as feministas mais velhas não fossem à Marcha das Vadias por diversas razões - entre elas, pela própria ideia de que a marcha seria "algo das jovens", o que em sua visão já refletiria uma posição "adultocentrada", isto é, que "atribui significados de menor relevância às práticas organizadas pelas jovens feministas".

Já ao conversar sobre a ausência de feministas mais velhas com Laura, ela afirmou discordar da ideia de que as "históricas" não participariam apenas porque não se sentiriam convidadas, ou porque seria algo "das jovens". Para ela, haveria também uma outra questão aí: a Marcha das Vadias não garantia, a algumas, o "palanque desejado". Não significaria um lugar de poder interessante a ser ocupado politicamente, quase sempre com vistas partidárias. E uma das razões disso acontecer seria "o microfone no chão": as pessoas que desejassem fazer alguma fala nas marchas não subiriam nos carros de som, como é comum em diversos protestos, mas deveriam falar do chão. Sobre o microfone no chão, Laura relatou que esta foi a discordância, em 2014, que tomou conta do Fórum Goiano de Mulheres, na organização de eventos importantes de sua alçada, como o 8 de março, gerando um boicote ao próprio Fórum.

Em 2014, tivemos um racha no Fórum Goiano. (...) Tomamos decisões que contrariaram alguns grupos políticos. Qual foi a decisão que contrariou: microfone no chão. Parece uma bobagem, mas isso foi o grande pivô do problema do Fórum de Mulheres de 2014. Porque em 2014, logo nesse ano teria eleição e nos próximos teria novamente eleição. E o Fórum, como é um lugar de poder forte, que tem um imaginário aqui, tem 40 instituições e grupos que assinam junto, ele tem um status. E o Fórum tava reunido, tinha a ideia de articular os grupos feministas de Goiânia e entorno. E esse interesse tinha algum sucesso. Tava conseguindo alguma coisa nisso. E em alguns momentos isso se agiganta, como no 8 de março. E aquele lugar do microfone, principalmente em cima do carro de som, liderando uma massa de mulheres, passou a ser uma coisa do imaginário das mulheres que disputavam espaços de poder como candidatas a vereadora, a deputada, como assessoria de candidatas... [...] A partir do momento que a gente decide que a marcha de 8 de março de 2014 não vai ter microfone no alto, vai ser no chão, a gente começou a sofrer boicotes, e sofrer o desgaste da pequena política... então a coisa degringolou (Fala de interlocutora. Entrevista presencial com Laura. Goiânia, março de 2017).

Aqui, considero importante ressaltar que tive o insight de usar os conceitos de "performances etário-geracionais" e "performances de protesto" neste trabalho a partir de uma fala de outra interlocutora, Luísa, 22, que se considera uma jovem feminista, branca, de classes médias e universitária, e que afirmou ter ido à Marcha das Vadias de Goiânia uma única vez, no ano de 2015 - não gostando muito do que presenciou. De acordo com ela: "só as pessoas jovens expõem o corpo nesses atos, enquanto as mais velhas ficam no microfone. Acho algo meio 'vão lá fazer essas loucuras enquanto a tia aqui faz o trabalho sério"' (Conversa por Facebook, caderno de campo. Goiânia, junho de 2016, grifo meu).

Sendo assim, sua fala me remeteu às possibilidades de interpretações hierarquizadas 
das performances de protesto nos atos militantes, nas quais a exposição do corpo (ainda que acompanhada de palavras de ordem e gritos feministas) poderia ser olhada, por algumas, como um lugar secundário em relação ao uso verbal no microfone.

Quando Laura afirmou que algumas feministas não iriam à Marcha das Vadias goiana "por falta de palanque", penso que não se trata aqui de tomar tal afirmação como uma verdade em si - afinal, apenas cada militante poderia responder em seu íntimo as razões pelas quais não participaria de algo. Entretanto, sua mera suposição de que a $\mathrm{MdV} / \mathrm{GO}$ não seria um lugar desejável para algumas por não lhes garantir a visibilidade política, já reflete que tal análise é, de algum modo, possível para alguém.

$\mathrm{Na}$ visão de Luísa, a possibilidade de hierarquização estaria atravessada por uma prática "adultocentrada" advinda das militâncias, cujo histórico partidário coadunaria com essa imagem. Isso inclusive seria traduzido no uso da expressão "tia” para se referir a essas feministas. Mas como será que as organizadoras e demais jovens feministas encarariam isso?

Decidi então apresentar a fala de Luísa para a interlocutora Tina, que é negra, de classes populares, bissexual e com 35 anos à época da pesquisa. Tina a princípio apontou a necessidade de pensar que há várias formas de falar na marcha e que seria arriscado pensar em uma interpretação hierarquizada entre elas - seja entre os corpos e o microfone, seja entre estes e os tambores da bateria, formados pelo Batuque Feminista goiano, um grupo de bateria formado principalmente por mulheres negras.

É interessante que Tina ressaltou, por exemplo, não ser adepta do peitaço por considerar os riscos de hiperssexualização de seu corpo negro, já historicamente hiperssexualizado, ao aderir a tal performance. Sendo assim, o Batuque Feminista e os seus tambores - que trazem também aspectos candomblecistas, considerando que Margarida, a responsável pelos ensaios do grupo, é mãe de santo e que algumas militantes negras inclusive frequentavam a sua casa de santo - poderiam ser interpretados como uma performance de protesto atravessada por marcadores da diferença, tendo a "raça"/cor evidenciada nesse contexto.

Posteriormente, Tina também colocou como a (falta de) intimidade com o microfone, advinda de mais tempo de militância, poderia afastar mulheres mais jovens, principalmente as mulheres negras, desta performance de protesto.

Sobre o microfone: eu realmente acredito que ele pode ser mais aberto. Mas tem que haver um processo de construção por parte das mulheres lá dentro, né? Tipo assim, de entender a importância de pegar o microfone. A gente é educada pra não falar. Os homens que falam. $E$ as mulheres que tomam a liberdade de falar, geralmente já passaram por esse processo, já desconstruíram isso, entendeu? Por isso que eu digo: a marcha, ela tinha que ter mais atividades de desconstrução ali, porque às vezes até nós mesmas ainda reproduzimos algumas coisas. E o medo de falar lá na frente, sabe? (...) Então eu não sei se vale a pena dizer "as mais velhas estão se apropriando", ou se ainda faltam muitos detalhes aí nesse processo de ter a consciência de que ela [a jovem], sobretudo a jovem negra pode falar. Então eu acho que é muito subjetivo isso. Mas sim, acho que mais pessoas precisam falar (Caderno de campo, entrevista presencial, Goiânia, junho de 2016, grifos meus).

Nesse sentido, seguindo a perspectiva de Tina, aprender com as mais velhas, inclusive com as "históricas", um modo falar, ainda que se questione $o$ quê se fala e se faça uma escolha deliberada por outros modos, poderia ser um aprendizado e uma aliança intergeracional interessante. Ainda sobre a fala no microfone, Maria foi a organizadora e interlocutora que pude perceber com mais intimidade e com amplo uso dessa performance de protesto nos atos. Ela também foi candidata a vereadora em 2016 e afirmou contabilizar em sua história mais de uma década de militância. Quando lhe apresentei algumas questões sobre os usos do microfone, seus apontamentos foram interessantes, inclusive no que tange os outros espaços de militância para onde a prática do "microfone no chão" foi levada.

Essa questão do microfone, eu to me perguntando muito, porque...[..] eu sou da comunicação, sou muito da palavra. Eu também fico com muito receio de não tá deixando outras meninas irem. Eu me preocupo muito com isso. E putz, hoje no 
movimento [Frente Popular, organizado pelo PT] tem militante nem olhando na minha cara, porque questionei que centraliza a fala, levei a metodologia da Marcha das Vadias.. E putz, a Marcha foi fundamental, Paula, foi fundamental, acho que até nós feministas nos educamos mais, sabe? Pra levar isso por exemplo pro movimento sindical, e aí você leva essa metodologia pra outros movimentos, e o povo não entende não. Não entende não, e depois elogia quando você faz uma marcha com o microfone aberto e no chão. Hoje mesmo a gente começou a marcha com o microfone no carro de som por uma questão de crítica anterior, de visibilidade, aí falamos "Vamos descer". Aí beleza, microfone aberto e no chão. Isso faz com que outras pessoas participem. Mas eu vejo que ainda há mulheres que não... Eu fico sem saber o que fazer, sabe? Pra mim, todo mundo tinha que falar um pouco. E elas tinham que treinar. Todo mundo fica nervosa, fica tímida, mas... É treino, eu sempre falo pras meninas mais novas, é treino, tem que ir pra prática (Conversa por áudio no Whatsapp, caderno de campo, Goiânia, 2016).

\section{Considerações finais}

Conforme apresentado, sem o intuito de fechar ou cristalizar quaisquer análises, penso que o campo da Marcha das Vadias de Goiânia/ GO possa ser rentável para reflexões que levem em consideração aspectos geracionais presentes naquilo que Fuentes (2015) chama de "performances de protesto". Estas, por sua vez, poderiam se interseccionar, de modos variados, com "performances etário-geracionais" (Henning, 2014) e com a própria noção de experiências adquiridas de práticas de militância. É importante ressaltar que Henning utilizará este conceito para pensar como seus interlocutores terão performances etário-geracionais que não corresponderão às expectativas geradas por suas idades. O uso que faço aqui, no entanto, leva em consideração um outro contexto, relacionado ao meu campo e às noções de idade/geração que nele aparecem. Nesse sentido, em meu campo, as idades e gerações por vezes surgem como elementos que justificariam e explicariam as performances de protesto realizadas ou refutadas, em tentativas talvez de coerências, como na fala da interlocutora Izadora, quando diz "é uma questão de geração".

Além disso, é importante dizer como o aspecto racial também precisa ser levado em consideração nesse campo, pois conforme Tina e outras militantes negras ressaltaram em entrevista, o risco de "hiperssexualização" de determinadas performances de protesto, a exemplo do peitaço, quando feitas especialmente por mulheres negras poderia fazer com que estas tivessem mais restrições do que mulheres brancas aos usos de nudez ou semi-nudez, com possibilidades de impacto em suas performances de protesto. Obviamente, não se trata aqui de uma análise totalizante.

Pensar tais performances não é sinônimo, de modo algum, de determinação fechada de comportamentos associados a algum grupo. A proposta é muito mais de pensar e refletir sobre tensões e aberturas, incluindo as geracionais e aquelas associadas a outros marcadores. Alguns dos aspectos que me chamaram atenção foram, por exemplo, as formas pelas quais muitas interlocutoras, de diferentes idades, acionaram as noções geracionais e de idade para justificar seus posicionamentos, ideias e comportamentos, inclusive os de cunho feminista e que participam de sua militância.

Falas como "ouvi de minha mãe e de minha avó" e "minha mãe não iria entender" poderiam denotar, nesse sentido, continuidades e/ou rompimentos, na medida em que as gerações sequentes colocariam posições mais ou menos inteligíveis para as anteriores. Sendo assim, ao refletir sobre as práticas de jovens feministas nos mais diversos campos, como nas Marchas das Vadias, poderia-se refletir sobre as performances de protesto, com os corpos sendo utilizados de modo subversivo com sua exposição, por vezes baseada na nudez e no uso de roupas e indumentárias provocativas, incluindo aqui os batuques e tambores, aliadas então às performances etário-geracionais. Nestas, as ideias de juventude seriam retomadas como aquelas expostas por Debert (2010), de dinamismo e criatividade, ao mesmo tempo que sugere na noção de juventude o que as falas das jovens feministas entrevistadas no trabalho de Oliveira e Gonçalves (2014) apontaram, com as ideias de força, novidade e rebeldia. 
Dessa forma, alguns caminhos se abrem para pensar os pontos que o campo me colocou. A decisão de quem fala e de como fala, assim como de quem marcha e como marcha - num movimento feminista jovem como a MdV/GO e inserida num contexto de feminismos contemporâneos parece atravessada por intersecções entre corpo, gênero, "raça"/cor, classe, além de idade/"geração", não desconsiderando outras possíveis, como sexualidade.

Como a interlocutora Tina sugeriu, não se trataria simplesmente de criar hierarquias sobre como essas falas e expressões são feitas, mas de pensá-las relacionalmente: por que um microfone no chão, afinal, gera tantas dissidências? Se a nudez de um corpo poderia ser interpretada como possível "exibicionismo", o que dizer sobre as falas do alto dos carros de som, tão comuns a determinadas práticas militantes?

Em linhas gerais, busquei apresentar alguns desafios associados às tentativas de construção de coalizões políticas em torno de programas e agendas feministas compartilhadas entre gerações - tarefa árdua, permeada por contradições, diferenças, disputas de poder e nem sempre alcançada com o êxito esperado. Pensar impasses feministas em termos etário-geracionais também pode ser uma forma de entender, de modo frutífero, os próprios dilemas, deslocando o olhar das rupturas para as possibilidades de continuidades e alianças.

Se as coalizões por vezes são bem-sucedidas, em outras também é possível que elas não aconteçam. Entender que a possibilidade de espaços distintos não mina o desejo por alianças e por ações conjuntas, ainda que permaneçam guardadas as devidas especificidades, também é uma forma de buscar uma compreensão, em um cenário mais geral, daquilo que nos une. Não lutamos com os mesmos corpos, nem das mesmas formas. Mas eles continuam em campo. Resistem, cada um à sua maneira. Apesar de.

\section{Referências:}

ALVAREZ, Sonia. "Para além da sociedade civil: reflexões sobre o campo feminista”. In: Cadernos Pagu, Campinas, v. 43, p. 13-56, 2014.
BATISTA, Paula Nogueira Pires. "Nós comemos e regurgitamos": feminismos transnacionais e coalizões potenciais a partir da Marcha das Vadias deGoiânia/GO. 2017.162f. Dissertação(Mestrado em Antropologia Social), Universidade Federal de Goiás, UFG, Goiânia, 2017.

BRAZ, Camilo. "De Goiânia a 'Gayânia': notas sobre o surgimento do mercado" GLS" na capital do cerrado". In: Revista Estudos Feministas, v. 22, n. 1, p. 277-296, 2014.

COSTA, Ana Alice Alcântara. "O Movimento Feminista no Brasil: dinâmica de uma intervenção política”. In: MELO, Hildete Pereira et al (Orgs.). In: Olhares Feministas. Brasília: Ministério da Educação, 2006. p. 51-82.

DEBERT, Guita Grin. "A dissolução da vida adulta e a juventude como valor". In: Horizontes antropológicos, Porto Alegre, v. 16, n. 34, p. 49-70, 2010.

FACCHINI, Regina; FRANÇA, Isadora Lins. "Apresentação: Dossiê Feminismos Jovens". In: Cadernos Pagu, v. 36, p. 9-24, 2011.

FÓRUM GOIANO DE MULHERES. O que é o Fórum Goiano de Mulheres - FGM? Disponível em: https://www.facebook.com/pg/AMB. FGM/about/?entry_point=page_nav_about_ item\&ref=pge_internal. Acesso em: $12 \mathrm{fev}$. 2017.

FUENTES, Marcela A. "Performance, política e protesto". 2015. Disponível em: <http://scalar. usc.edu/nehvectors/wips/performance-politicsand-protest-1>. Acesso em: 12 mar. 2016.

GOMES, Carla; SORJ, Bila. "Corpo, geração e identidade: a Marcha das vadias no Brasil". In: Sociedade e Estado, Brasília, v. 29, n. 2, p. 433447, 2014.

GONÇALVES, Eliane; PINTO, Joana Plaza. "Reflexões e problemas da "transmissão" intergeracional no feminismo brasileiro". In: Cadernos Pagu, Campinas, n. 36, p.25-46, jan./ jun. 2011. 
GONÇALVES, Eliane, FREITAS, Fátima

Regina Almeida de; OLIVEIRA, Elismênnia Aparecida. "Das idades transitórias - as "jovens" no feminismo brasileiro contemporâneo, suas ações e seus dilemas". In: Revista Feminismos, Salvador, v. 1, n. 3, 2014. Disponível em: http:// www.feminismos.neim.ufba.br/index.php/ revista/article/viewFile/81/79. Acesso em: 10 out. 2016

GROPPO, Luís Antonio. “Teorias críticas da juventude: geração, moratória social e subculturas juvenis”. In: Em Tese, v. 12, n. 1, p. 4-33, 2015.

HENNING, Carlos Eduardo. Paizões, tiozões, $e$ tias e cacuras: envelhecimento, meia idade, velhice e homoerotismo masculino na cidade de São Paulo. 2014. 422f. Tese (Doutorado em Antropologia Social) - Instituto de Filosofia e Ciências Humanas, Universidade Estadual de Campinas, Campinas, 2014.

MANNHEIM, Karl. O problema sociológico das gerações. In: Marialice M. Foracchi (org). Karl Mannheim: Sociologia. São Paulo: Ática, pp. 6795, 1982

ROCHA, Maria José Pereira; BICALHO, Elizabete (Coords.). FARIA, Gisele Justiniano de (Colab.). Luta e resistência de mulheres em Goiás (1930-1993). Goiânia: Ed. UCG, 1999.

RODRIGUES, Rubia Carla Martins. As vozes que não se calaram: história e memória do movimento feminista em Goiânia. 2010. 152f. Dissertação (Mestrado em História) - Departamento de Ciências Humanas e da Terra, Pontifícia Universidade Católica de Goiás, Goiânia, 2010.

SARTI, Cynthia. "O início do feminismo sob a ditadura no Brasil: o que ficou escondido". In: Anais do. XXI Congresso Internacional da LASA (Latin American Studies Association), Chicago, set.1998. 
